\title{
Impact of Biomechanical Forces on Antibiotics Release Kinetics from Hydroxyapatite Coated Surgical Fixation Pins
}

\author{
Mirjam Lilja ${ }^{1,2}$, Jan H. Sörensen ${ }^{3}$, Torben C. Sörensen ${ }^{4}$, Maria Åstrand ${ }^{2}$, Philip Procter ${ }^{5,6}$, \\ Hartwig Steckel $^{3^{*}}$, Maria Strømme ${ }^{1^{*}}$ \\ ${ }^{1}$ Division for Nanotechnology and Functional Materials, Department of Engineering Sciences, The Ångström Laboratory, Uppsala \\ University, Uppsala, Sweden; ${ }^{2}$ Sandvik Coromant AB, Stockholm, Sweden; ${ }^{3}$ Department of Pharmaceutics and Biopharmaceutics, \\ Christian Albrecht University Kiel, Kiel, Germany; ${ }^{4}$ Stryker Trauma GmbH, Schönkirchen, Germany; ${ }^{5}$ Stryker Trauma AG, Selzach, \\ Switzerland; ${ }^{6}$ School of Engineering and Design, Brunel University, Uxbridge, UK. \\ Email: "hsteckel@pharmazie.uni-kiel.de,maria.stromme@angstrom.uu.se
}

Received July $16^{\text {th }}, 2013$; revised August $16^{\text {th }}, 2013$; accepted September $12^{\text {th }}, 2013$

Copyright (c) 2013 Mirjam Lilja et al. This is an open access article distributed under the Creative Commons Attribution License, which permits unrestricted use, distribution, and reproduction in any medium, provided the original work is properly cited.

\begin{abstract}
This work investigates the impact of biomechanical wear and abrasion on the antibiotic release profiles of hydroxyapatite (HA) coated fixation pins during their insertion into synthetic bone. Stainless steel fixation pins are coated with crystalline $\mathrm{TiO}_{2}$ by cathodic arc evaporation forming the bioactive layer for biomimetic deposition of Tobramycin containing HA. Tobramycin is either introduced by co-precipitation during HA formation or by adsorption-loading after HA deposition. The samples containing antibiotics are inserted into bone mimicking polyethylene foam after which the drug release is monitored using high performance liquid chromatography. This analysis shows that HA coating wear and delamination significantly decrease the amount of drug released during initial burst, but only marginally influence the sustained release period. Spalled coating fragments are found to remain within the synthetic bone material structure. The presence of HA within this structure supports the assumption that the local release of Tobramycin is not only expected to eliminate bacteria growth directly at the pin interface but as well at some distance from the implant. Furthermore, no negative effect of gamma sterilization could be observed on the drug release profile. Overall, the observed results demonstrate the feasibility of a multifunctional implant coating that is simultaneously able to locally deliver clinically relevant doses of antibiotics and an HA coating capable of promoting osteoconduction. This is a potentially promising step toward orthopaedic devices that combine good fixation with the ability to treat and prevent post-surgical infections.
\end{abstract}

Keywords: Hydroxyapatite; Fixation Pin; Tobramycin; Coating Wear; Drug Release; Gamma Sterilization

\section{Introduction}

External fixators are commonly used for fracture stabilization in certain trauma patients [1]. The bone-screw interface has been identified as "the common weak link in fracture fixation" [2]. Studies report that a rate of pin loosening up to $80 \%$ for standard metal pins and loose pins affect not only fracture fixation but also cause infections [3-5]. The concept of applying a biocompatible and bioactive hydroxyapatite (HA) coating onto metallic implants as functional surface coating has been verified to be an effective way of improving the bone-pin interface strength [6-8]. Several animal and clinical studies con-

*Corresponding author. firmed the osteoconductive properties of HA coatings resulting in enhanced stability at the pin-bone interface and hence reduced pin loosening [9-11].

Nanoporous HA coatings deposited biomimetically (HA-B) have shown promising properties as drug delivery vehicles [12-20]. Antibacterial drugs eluting from such HA coatings provide a possibility to combat bacteria at the implant site and hence contribute towards minimizing the risk of implant related infections post-surgery. Despite excellent properties of HA as a biomaterial, deficient mechanical performance including brittleness, low tensile strength and impact resistance has restricted its application in many load-bearing applications $[6,7,21]$. 
Plasma sprayed HA coatings (HA-P) have been shown to delaminate from the implant substrate $[22,23]$ or expel coating segments [24] due to low cohesive and adhesive strength. The bond strength of HA-P coatings is not only dependent on the coating characteristics but also on coating thickness and the type and design of the implant used [21]. For example, the use of a thin $\mathrm{TiO}_{2}$ bonding layer connecting the HA-P coating to the metallic implant has been shown to induce strong adhesion of such coatings to the implant [25].

Despite the poor biomechanical properties, HA coating delamination has only been identified in some animal studies [26]. Delaminated particles were found to be surrounded by bone and not associated with a foreign-body cell reaction [27].

To date, only a few investigations on the insertion and wear characteristics of HA coatings are available [28,29]. While the use of HA-B coatings as drug delivery vehicle has been extensively studied, to the best of our knowledge no attempts have been made to establish a correlation between the insertion characteristics of HA-B coated implants and the drug release profiles from such implant surfaces.

The aim of this study is to analyze the impact of biomechanical forces on the HA-B coating wear and correlate the latter to the in vitro drug release properties of the coatings. To bring the concept of antibiotic loaded HA-B coatings on fixation pins further towards clinical practice, the release properties of Tobramycin loaded HA-B coated fixations pins are also evaluated after gamma-sterilization.

\section{Material and Methods}

\subsection{Substrate Materials and Coating Deposition}

A crystalline, anatase phase dominated $\mathrm{TiO}_{2}$ coating was deposited on stainless steel fixation pins (Ø $4 \mathrm{~mm}, 90$ $\mathrm{mm} \times 30 \mathrm{~mm}$ ), as reported earlier in detail [30]. The pins were either covered with a biomimetic coating [31] obtained through immersion for 6 days in Dulbecco's Phosphate Buffered Saline (PBS), denoted HA-B, or with a co-precipitated, drug containing HA coating as described by Sörensen et al. [28] and denoted Co-4.

\subsection{Preparation of Drug Loaded Samples}

Tobramycin was incorporated into HA-B coated pins using a previously described adsorptive loading method [15]. Briefly, two types of drug loading methods were carried out to produce samples with the extensions "RT" (room temperature) and "PHT" (pressure and high temperature) to their sample names, respectively. All samples were made in triplicate for both loading methods being studied. During RT loading, the HA coated pins were placed for $5 \mathrm{~min}$ in tubes containing $5 \mathrm{ml}$ of To- bramycin stock solution with a concentration of 20 $\mathrm{mg} / \mathrm{ml}$. PHT samples were prepared by placing the HAcoated pins and $30 \mathrm{ml}$ of stock solution containing 20 $\mathrm{mg} / \mathrm{ml}$ Tobramycin in a stainless steel tube under an applied pressure of 6 bar and a temperature of $90^{\circ} \mathrm{C}$. For the preparation of Co-4 samples, $\mathrm{TiO}_{2}$ coated pins were in a first step coated with a thin HA layer through immersion for 3 days in $50 \mathrm{ml} \mathrm{PBS}$ at $60^{\circ} \mathrm{C}$ followed by immersion in PBS with an antibiotic concentration of 4 $\mathrm{mg} / \mathrm{ml}$ for 6 days at $37^{\circ} \mathrm{C}$. After the loading procedure, the samples were placed for drying in an oven at $37^{\circ} \mathrm{C}$ for 24 hours.

\subsection{Insertion into Polyethylene Foam}

Biomechanical properties were evaluated using polyurethane (25 PU) foam blocks (20 mm $\times 20 \mathrm{~mm} \times 4 \mathrm{~mm}$ ) mimicking spongy bone quality. 25 PU was chosen, since preliminary tests demonstrated that this particular grade induced more severe coating wear-effects after insertion compared to higher density synthetic bone qualities reflecting cancellous bone structures [32]. Three fixation pins of each sample type were loaded with Tobramycin via adsorption at room temperature, denoted as HA-B_RT_BML, or under elevated temperature and pressure, denoted as HA-B_PHT_BML followed by biomechanical insertion. Co-precipitated samples denoted as Co-4_BML were also tested in triplicate. Insertion was performed vertically without predrilling at a rotation speed of 50 rotations per minute over the full thread length of the coated pin. The pin was removed from the bone model materials by cutting two notches from both sides into the discs and plates with a distance of approximate $3 \mathrm{~mm}$ towards the center of the pin resulting in two separate pieces of bone model material. The bone model pieces were subsequently broken into two halves by applying an abrupt mechanical force, thus freeing the pin.

\subsection{Gamma Sterilization}

Gamma Sterizlization of HA-B_PHT samples was carried out by Beta-Gamma-Service GmbH \& Co KG, Wiehl, Germany with a minimum dose of $25.4 \mathrm{kGy}$ and the sterilized samples were denoted as HA-B_PHT gamma sterilized.

\subsection{Antibiotic Release}

High performance liquid chromatography (HPLC) was used to quantify the released drug content as well as the release kinetics of the three different sample types after insertions. The measurements were performed and modified according to the British Pharmacopoeia [33] and Fabre et al. [34] using pre-column derivatization of the aminoglycoside antibiotic. Following the insertion into 
25 PU foam, the samples were placed in round bottom test tubes containing $5 \mathrm{ml}$ of $\mathrm{PBS}$ at $37^{\circ} \mathrm{C}$. The amount of Tobramycin released from the samples was measured at different time points to study both initial and sustained release properties, in line with previously published procedures [15].

\subsection{Characterization}

After insertion and drug release tests the durability of the HA-B coatings was evaluated with a Supra 40 (Zeiss) Scanning Electron Microscope (SEM). Coating thicknesses of the as-deposited samples were measured with SEM on coating cross sections that were specially created using a razor blade. To verify that no Tobramycin remained in the samples after the release measurements, the HA-B and Co-4 coatings were dissolved by adding hydrochloric acid to the release medium (until a $\mathrm{pH}$ of 2 was obtained) and analyzing the release medium with HPLC.

\section{Results}

\subsection{Coating Thickness}

SEM analysis of the HA-B coated fixation pins revealed a coating thickness of approximate $5-6 \mu \mathrm{m}$, whereas Co-4 samples exhibited a thickness of only $2.5-3 \mu \mathrm{m}$, as described earlier $[15,28]$. Both sample types possessed higher thicknesses in the thread valleys while lower values were measured at the thread crests.

\subsection{Coating Wear}

As visualized by the SEM images in Figure 1, the coatings of all sample types under study were mechanically affected by insertion into 25 PU foam. The flute of the fixation pin maintained its “as-deposited” morphology for all samples types and showed only stochastic areas of flake off (Figures 1(b), (e) and (h)). Nevertheless, differences in the coating deterioration could be observed with respect to the drug loading method applied. While RT samples showed preferential HA-B coating delamination at screw tops (Figures 1(b) and (c)), only minor impact of the biomechanical forces could be seen on the HA coating in screw valleys and at the screw tip (Figure 1(a)) for such samples. PHT samples exhibited coating wear patterns similar to the RT samples (Figures 1(d)-(f)). However, the coating delamination within the thread valleys for the PHT samples was somewhat larger (Figure 1(f)). Drug incorporation via co-precipitation resulted in only minor coating wear after insertion. In comparison to adsorptive drug loaded samples, Co-4 samples exhibited major flake-off at the pin entry site (Figure $\mathbf{1 ( g ) )}$ and only few areas of delamination along the screw length (Figure 1(i)).

As displayed by the images in Figure 2, the HA-B coating delaminated from the $\mathrm{TiO}_{2}$ coated pin surface seems to remain within the porous foam structure. The white discoloration of the insertion material, Figure 2(a), represents the HA-B coating delaminating from the pin during insertion. A higher concentration of HA-B coating

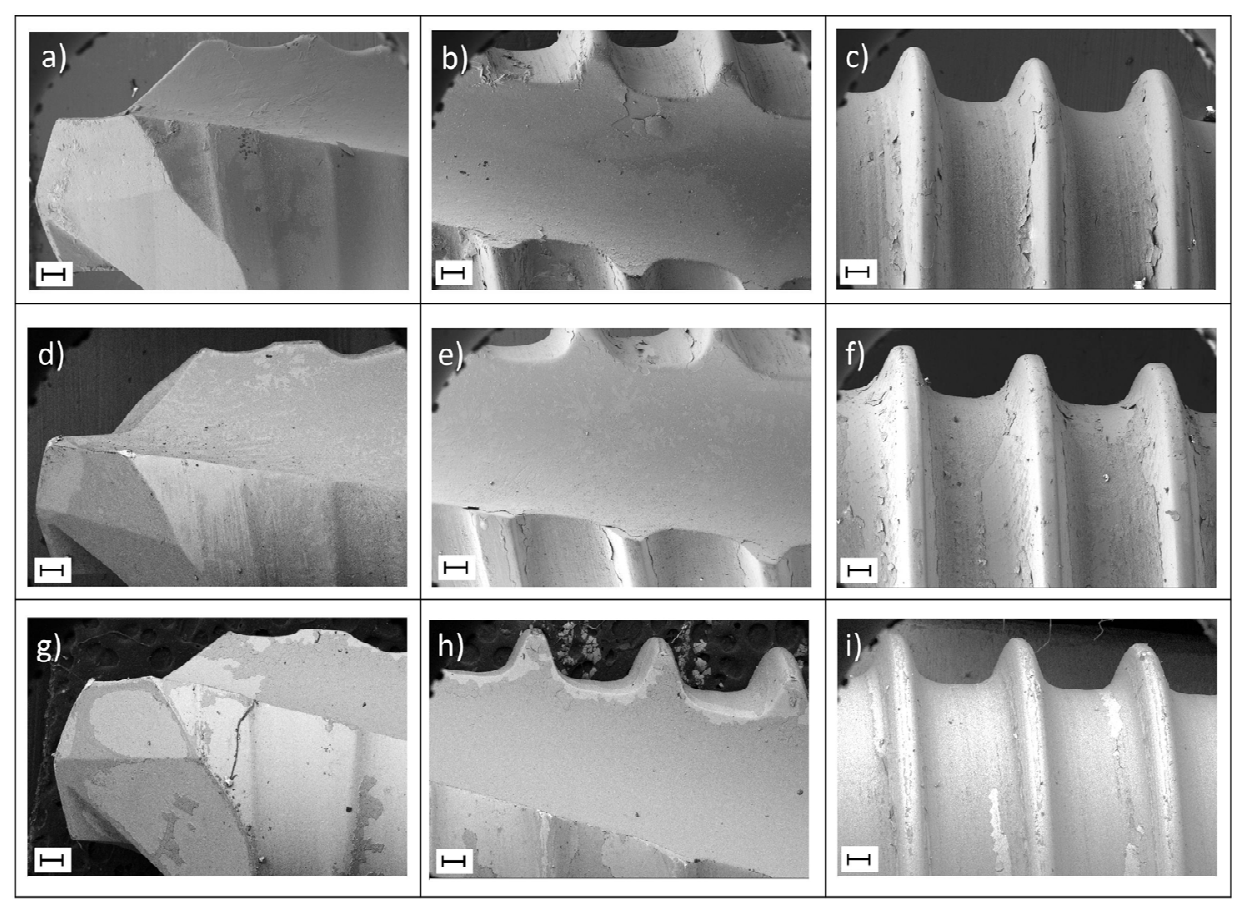

Figure 1. SEM images (scale bars $200 \mu \mathrm{m}$ ) of RT-samples (upper panels), PHT samples (middle panels) and Co-4 samples (lower panels) after insertion into 25 PU foam and subsequent drug release in PBS. 


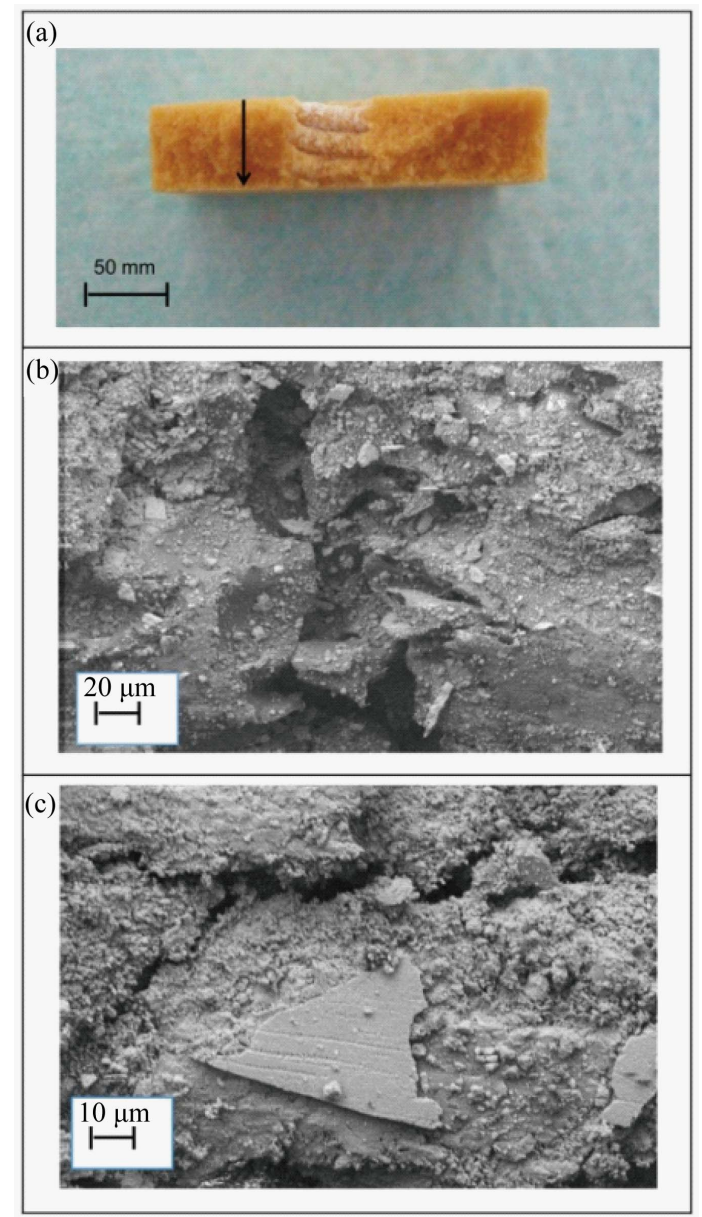

Figure 2. Photo (a) and SEM images (b), (c) of 25 PU foam after insertion. The insertion direction is indicated by an arrow (a). SEM images were taken at an insertion depth of approximate $2 \mathrm{~mm}$ from the pin entry point. The scale bars in panels (a), (b) and (c) are $50 \mathrm{~mm}, 20 \mu \mathrm{m}$ and $10 \mu \mathrm{m}$, respectively.

could be observed at the pin entry side, whereas less staining of the material could be seen with increasing insertion depth. HA-B coating flakes could be identified in the foam structure, as shown by the SEM image taken at a depth of $2 \mathrm{~mm}$ from the pin entry point (Figure 2(b)). Within the foam structure, the delaminated HA-B fragments showed a flake like morphology, which reflects the "as-deposited" coating morphology [15]. The size of delaminated HA-B fragments, Figure 2(c), is comparable to those observed during conventional scratch testing of the $\mathrm{TiO}_{2} / \mathrm{HA}-\mathrm{B}$ coating system [32].

\subsection{Drug Release}

Tobramycin release profiles were evaluated by HPLC. For all samples under study, the Tobramycin release can be described by an initial burst release followed by a sustained release. The inserted samples (BML) released significantly lower amounts of drug during the initial 15 minute phase as compared to samples that had not been inserted into the bone model, Figure 3. The sustained release, however, seemed to be less effected by the insertion into $25 \mathrm{PU}$ foam. The longest release period under the prevailing conditions was detected for the PHT coated samples and lasted for 8 days, followed by PHT_ BML inserted samples showing a release up to 5 days. The samples loaded at room temperature demonstrated maximum release duration of 2 days.

The amount of Tobramycin for all sample types was above the minimum inhibition concentration (MIC) for Staphylococcus aureus for all time points measured, which corresponds to a Tobramycin concentration of 1 $\mathrm{mg} / \mathrm{ml}$ in the release medium [35].

Figure 4 displays the effect of insertion of Co-4 coated pins into $25 \mathrm{PU}$ on the drug release. The biomechanical forces significantly impacted the initial burst release and only slightly decreased the amounts of drug released at later time points. The total amount of Tobramycin released from the inserted samples was $~ 35 \%$ lower that the released amount from the Co-4 reference samples. These reference samples released a detectable amount of antibiotics for as long as 12 days [28], while the Co-4_BML samples demonstrated a release period of 8 days. For all time points under study the amounts of Tobramycin released was above the MIC for S. aureus for all time points measured.

\subsection{Impact of Gamma Sterilization}

Figure 5 describes the impact of gamma sterilization on the amount of Tobramycin released from HA-B_PHT coated fixation pins. No significant difference between

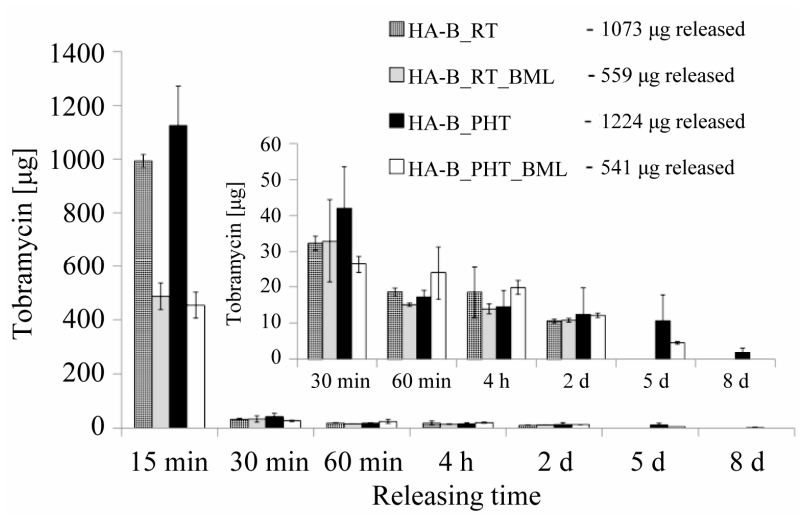

Figure 3. Non-cumulative amount of Tobramycin released in $37^{\circ} \mathrm{C}$ PBS from HA-B coated pins after RT and PHT loading in a solution containing $20 \mathrm{mg} / \mathrm{ml}$ of the antibiotics and following insertion into 25 PU foam (BML samples). Release results from mechanically untreated RT and PHT samples are incorporated as reference. Error bars denote the standard deviation of 3 measurements. The average total amounts of Tobramycin released from each sample type are also displayed. 


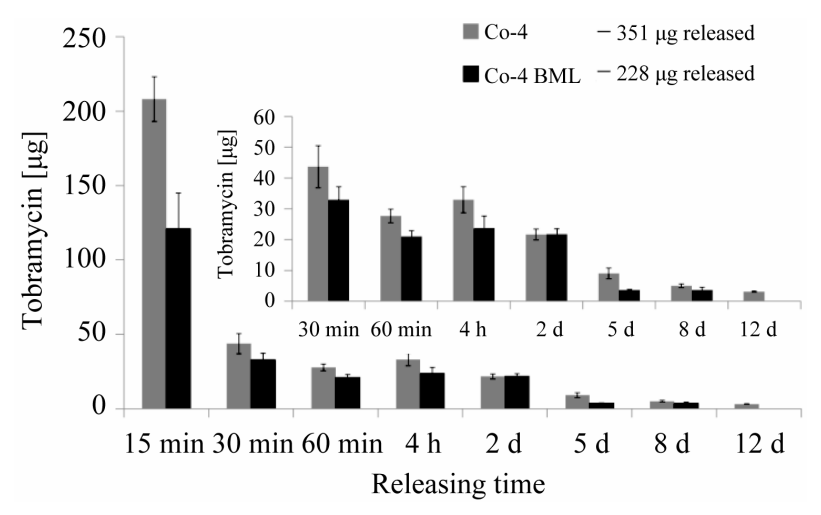

Figure 4. Non-cumulative amount of Tobramycin released in $37^{\circ} \mathrm{C}$ PBS from Co-4 coated pins after insertion into 25 PU foam (BML samples). Release results from mechanically untreated Co-4 samples are incorporated as reference. Error bars denote the standard deviation of 3 measurements. The average total amounts of Tobramycin released from each sample type are also displayed.

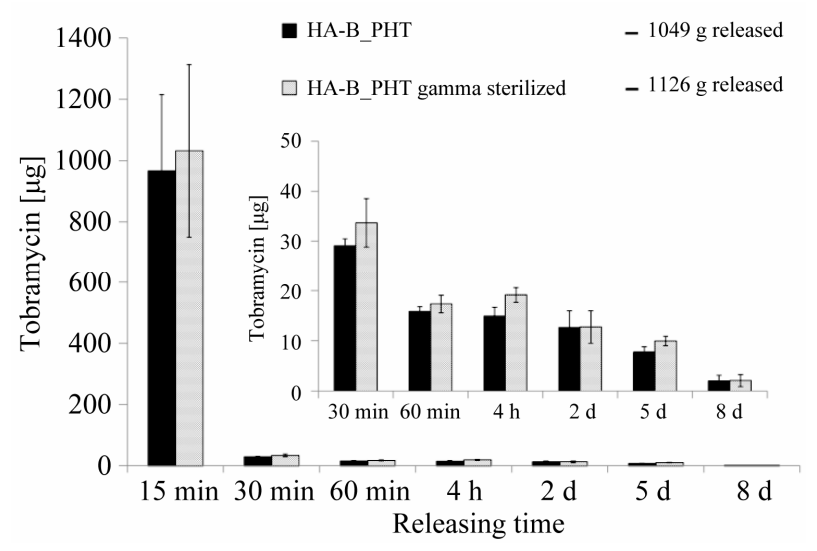

Figure 5. Non-cumulative amount of Tobramycin released in $37^{\circ} \mathrm{C}$ PBS from PHT loaded pins after gamma sterilization. Release results from PHT samples are incorporated as reference. Error bars denote the standard deviation of 3 measurements. The average total amounts of Tobramycin released from each sample type are also displayed.

the release kinetic from HA-B_PHT and its sterilized counterpart could be observed. The total release period lasted for 8 days and as for the samples tested above, the released amounts were found to be above the MIC of $S$. aureus for each time period under study. Furthermore, no additional peaks were identified in the HPLC analysis indicating that there is no detectable impact or inactivation of the drug molecule due to irradiation.

\section{Discussion}

Functionalizing implant surfaces with bioactive HA coatings has been shown to play an essential role in forming an intimate contact between the implant and bone [36]. However, for successful clinical implementation of such coatings the chemical and mechanical stability of the HA layer on the implant surface are considered to be important criteria [37,38]. Related to mechanical stability of HA-B coatings and the local release of drugs from such, the question arises of what would happen at the implant-bone interface in case of coating wear and loss. The data presented in this study confirm that insertion into bone mimicking foam material induces mechanical wear of the HA-B coatings. The biomechanical forces during insertion not only lead to compression and smearing of the coating but also to partial fragmentation and coating loosening from the $\mathrm{TiO}_{2}$ covered implant surface at high stress areas along the thread profile of the pin. While the total amount of coating wear is known to be dependent on the insertion torque and the total distance that the implant is moved when in contact with bone [29], also the bone properties have been shown to influence the forces required in screw insertion and pullout [29-41]. In agreement with literature [42], SEM images of the investigated sample types confirmed a high value of stresses at the pin entry site and at the thread tops giving rise to HA-B coating deterioration.

The observed coating wear led to a decrease of the amount of Tobramycin released for all sample types investigated, with the most significant reduction, $50 \%$, stemming from the initial burst period of the release. This shows that a substantial amount of antibiotics is superficially incorporated into the HA-B coating during loading by adsorption in agreement with earlier findings [15]. During the sustained release period following the initial burst, insertion-induced wear had only minor effects on the drug release process governed by released from deeper sections of the coating.

Co-precipitated samples suffered less coating wear-off than HA samples that were drug loaded after coating fabrication. This difference in coating wear may be related to the coating growth conditions, which could result in different mechanical coating properties or be connected to the lower coating thickness of the co-precipitated Co-4 samples [28]. The delaminated HA coating was found to remain within the synthetic bone materialfor all sample types. During in vivo bone insertion, the screw design, the friction at the coating interface as well as the bone density will be factors influencing the insertion torque and coating wear properties [43]. In fact, blood and fatty substances in vivo may act as lubricants and, hence, contribute to reducing the dry conditions prevailing at HA coating wear during insertion into synthetic bone [44]. Also, the delaminated HA fragments are still in place within the bone and will contribute positively to the antibiotic effect. Furthermore, the rather smooth topography of biomimetic HA coatings [15] could present an additional advantage to minimize insertion torques as well as to minimize heat evolution during insertion. 


\section{Conclusion}

The impact on Tobramycin release and coating wear of insertion into synthetic bone of fixation pins functionalized with antibiotics containing biomimetic HA coatings has been investigated. The investigated coatings were either prepared by co-precipitated of antibiotics during HA formation or by adsorption loading with antibiotics post HA deposition. All coatings under study were affected by insertion into the 25 PU synthetic bone material; at high stress areas of the pin surface coating delamination was observed leading to a significant reduction in the amount of antibiotics released in vitro during the first 15 minutes of release. However, the insertion had only minor effects on the sustained drug release period lasting for 5 and 8 days, respectively, for the adsorption-loaded and co-precipitation-deposited coatings. The delaminated coating fragments were found to remain within the synthetic bone material structure. Hence, the in vitro observed reduction of the initial burst effect will most likely not prevail in vivo and the sustained release is expected to not only eliminate bacteria directly at the pin surface but also at some distance from the implant. With respect to the higher concentration of delaminated HA coating found at the pin entry site of the bone model materials, a high concentration of antibiotic can be expected to be delivered at the insertion point of the implant. The pin entry site is a likely pathway for bacteria to infiltrate during and post-surgery, hence, a high local concentration at this site is potentially beneficial. The drug release profile of all HA coated implants under study was further shown to be unaffected by gamma sterilization. This demonstrates that the incorporation of drugs into nanoporous HA coatings represents a feasible approach even when producing functional, therapeutic coatings, where the drugs are industrially-incorporated into the device (drug/device combination product).

\section{REFERENCES}

[1] J. Schalamon, T. Petnehazy, H. Ainoedhofer, E. B. Zwick, G. Singer and M. E. Hoellwarth, "Pin Tract Infection with External Fixation of Pediatric Fractures,” Journal of Pediatric Surgery, Vol. 42, No. 9, 2007, pp. 1584-1587. http://dx.doi.org/10.1016/j.jpedsurg.2007.04.022

[2] T. Miclau, A. Remiger, S. Tepic and R. Lindsey, "Mechanical Comparison of the Dynamic Compression Plate, Limited Contact-Dynamic Compression Plate, and Point Contact Fixator,” Journal of Orthopaedic Trauma, Vol. 9, No. 1, 1995, pp. 17-22. http://dx.doi.org/10.1097/00005131-199502000-00003

[3] J. Mahan, D. Seligson, S. L. Henry, P. Hynes and J. Dobbins, "Factors in Pin Tract Infections," Orthopedics, Vol. 14, No. 3, 1991, pp. 305-308.

[4] G. Pizá, V. L. Caja, M. A. Gonzalez-Viejo and A. Navarro, "Hydroxyapatite-Coated External-Fixation Pins:
The Effect on Pin Loosening and Pin-Track Infection in Leg Lengthening for Short Stature,” Journal of Bone \& Joint Surgery, Vol. 86B, No. 6, 2004, pp. 892-897. http://dx.doi.org/10.1302/0301-620X.86B6.13875

[5] H. G. Ahlborg and P. O. Josefsson, "Pin-Tract Complications in External Fixation of Fractures of Distal Radius," Acta Orthopaedica Scandinavica, Vol. 70, No. 2, 1999, pp. 116-118. http://dx.doi.org/10.3109/17453679909011246

[6] A. Moroni, L. Orienti, S. Stea and M. Visentin, "Improvement of the Bone Pin Interface with Hydroxyapatite Coating: An in Vivo Long Term Experimental Study," Journal of Orthopaedic Trauma, Vol. 10, No. 2, 1996, pp. 236-242. http://dx.doi.org/10.1097/00005131-199605000-00003

[7] Y. C. Tsui, C. Doyle and T. W. Clyne, "Plasma Sprayed Hydroxyapatite Coatings on Titanium Substrates. Part 1: Mechanical Properties and Residual Stress Levels,” Biomaterials, Vol. 19, No. 22, 1998, pp. 2015-2029. http://dx.doi.org/10.1016/S0142-9612(98)00103-3

[8] C. C. Berndt, G. N. Haddad, A. J. D. Farmer and K. A. Gross, "Thermal Spraying for Bioceramic Applications," Materials Science Forum, Vol. 14, No. 3, 1990, pp. 161173.

[9] A. Moroni, F. Vannini, M. Mosca and S. Giannini, "State of the Art Review: Techniques to Avoid Pin Loosening and Infection in External Fixation,” Journal of Orthopaedic Trauma, Vol. 16, No. 3, 2002, pp. 189-195. http://dx.doi.org/10.1097/00005131-200203000-00009

[10] R. Placzek, M. Ruffer, G. Deuretzbacher, E. Heijens and A. L. Meiss, "The Fixation Strength of HydroxyapatiteCoated Schanz Screws and Standard Stainless Steel Schanz Screws in Lower Extremity Lengthening: A Comparison Based on a New Torque Value Index: The Fixation Index," Archives of Orthopaedic and Trauma Surgery, Vol. 126, No. 6, 2006, pp. 369-373.

http://dx.doi.org/10.1007/s00402-006-0142-5

[11] A. Pommer, G. Muhr and A. David, "HydroxyapatiteCoated Schanz Pins in External Fixators Used for Distraction Osteogenesis: A Randomized, Controlled Trial," Journal of Bone and Joint Surgery, Vol. 84A, No. 7, 2002, pp. 1162-1166.

[12] M. J. Raschke and G. Schmidmaier, "Biological Coating of Implants in Trauma and Orthopedic Surgery," Unfallchirurg, Vol. 107, No. 8, 2004, pp. 653-663.

[13] S. Piskounova, J. Forsgren, U. Brohede, H. Engqvist and M. Strømme, "In Vitro Characterization of Bioactive Titanium Dioxide/Hydroxyapatite Surfaces Functionalized with BMP-2,” Journal of Biomedical Materials Research Part B, Vol. 91B, No. 2, 2009, pp. 780-787. http://dx.doi.org/10.1002/jbm.b.31456

[14] J. Forsgren, U. Brohede, H. Engqvist and M. Strømme, "Co-Loading of Bisphosphonates and Antibiotics to a Biomimetic Hydroxyapatite Coating,” Biotechnology Letters, Vol. 33, No. 6, 2011, pp. 1265-1268. http://dx.doi.org/10.1007/s10529-011-0542-7

[15] M. Lilja, J. Sörensen, U. Brohede, M. Åstrand, J. Arnoldi, P. Procter, H. Steckel and M. Strømme, "Drug Loading and Release of Tobramycin from Hydroxyapatite Coated 
Fixation Pins,” Journal of Materials Science: Materials in Medicine, Vol. 24, No. 9, 2013, pp. 2265-2274. http://dx.doi.org/10.1007/s10856-013-4979-1

[16] U. Brohede, J. Forsgren, S. Roos, A. Mihranyan, H. Engqvist and M. Strømme, "Multifunctional Implant Coatings Providing Possibilities for Fast Antibiotics Loading with Subsequent Slow Release," Journal of Materials Science: Materials in Medicine, Vol. 20, No. 9, 2009, pp. 1859-1867. http://dx.doi.org/10.1007/s10856-009-3749-6

[17] J. Forsgren, U. Brohede, S. Piskounova, A. Mihranyan, S. Larsson, M. Strømme and H. Engqvist, "In Vivo Evaluation of Functionalized Biomimetic Hydroxyapatite for Local Delivery of Active Agents," Journal of Biomaterials and Nanobiotechnology, Vol. 2, No. 2, 2011, pp. 149-154. http://dx.doi.org/10.4236/jbnb.2011.22019

[18] M. Lilja, J. Forsgren, K. Welch, M. Åstrand, H. Engqvist and M. Strømme, "Photocatalytic and Antimicrobial Properties of Surgical Implant Coatings of Titanium Dioxide Deposited though Cathodic Arc Evaporation,” Biotechnology Letters, Vol. 34, No. 12, 2012, pp. 2299-2305. http://dx.doi.org/10.1007/s10529-012-1040-2

[19] M. Lilja, C. Lindahl, W. Xia, H. Engqvist and M. Strømme, "The Effect of Si-Doping on the Release of Antibiotic from Hydroxyapatite Coatings," Journal of Biomaterials and Nanobiotechnology, Vol. 4, No. 3, 2013, pp. 237-241. http://dx.doi.org/10.4236/jbnb.2013.43029

[20] J. Åberg, U. Brohede, A. Mihranyan, M. Strømme and H. Engqvist, "Bisphosphonate Incorporation in Surgical Implant Coatings by Fast Loading and Co-Precipitation at Low Drug Concentrations,” Journal of Materials Science: Materials in Medicine, Vol. 20, No. 10, 2009, pp. 20532061. http://dx.doi.org/10.1007/s10856-009-3771-8

[21] L. Sun, C. C. Berndt, K. A. Gross and A. Kucuk, "Material Fundamentals and Clinical Performance of PlasmaSprayed Hydroxyapatite Coatings: A Review," Journal of Biomedical Materials Research, Vol. 58, No. 5, 2001, pp. 570-592. http://dx.doi.org/10.1002/jbm.1056

[22] H. W. Debissen, W. Kalk, H. M. de Nieuport, J. C. Maltha and A van deHooff, "Mandibular Bone Response to Plasma Sprayed Coatings of Hydroxyapatite,” International Journal of Prosthodontics, Vol. 3, No. 1, 1990, pp. 53-58.

[23] A. David, J. Eitenmueller, G. Muhr, A. Pommer, H. F. Baer, P. A. W. Ostermann and T. A. Schildhauer, "Mechanical and Histological Evaluation of HydroxyapatiteCoated, Titanium-Coated and Grit Blasted Surfaces under Weight-Bearing Conditions," Archives of Orthopaedic and Trauma Surgery, Vol. 114, No. 2, 1995, pp. 112-118. http://dx.doi.org/10.1007/BF00422838

[24] R. J. Friedman, J. Black, K. A. Gustke, W. M. Braunohler, W.D. Guyer and C. Savory, "Four to Six Year Results of Hydroxyapatite Total Hip Arthroplasty," 20th Annual Meeting of The Society of Biomaterials, 1994, p. 37.

[25] H. Kurzweg, R. B. Heimann, T. Troczynski and M. L. Wayman, "Development of Plasma-Sprayed Bioceramics Coatings with Bond Coats Based on Titania and Zirconia,” Biomaterials, Vol. 19, No. 16, 1998, pp. 1507-1511. http://dx.doi.org/10.1016/S0142-9612(98)00067-2

[26] W. N Capello and T. W. Bauer, "Hydroxyapatite in Or- thopedic Surgery,” In: H. U. Cameron, Ed., Bone Implant Interface, C.V. Mosby, St. Louis, 1994, pp. 191-202.

[27] T. W. Bauer, "Hydroxyapatite: Coating Controversies," Orthopedics, Vol. 18, No. 9, 1995, pp. 885-888.

[28] J. Sörensen, M. Lilja, T. Sörensen, M. Åstrand, P. Procter, M. Strømme and H. Steckel, "Co-Precipitation of Tobramycin into Hydroxyapatite Coatings,” unpublished.

[29] K. A. Gross and M. Babovic, "Influence of Abrasion on the Surface Characteristics of Thermally Sprayed Hydroxyapatite Coatings," Biomaterials, Vol. 23, No. 24, 2002, pp. 4731-4737. http://dx.doi.org/10.1016/S0142-9612(02)00222-3

[30] M. Lilja, K. Welch, M. Åstrand, H. Engqvist and M. Strømme, "Effect of Deposition Parameters on the Photocatalytic Activity and Bioactivity of $\mathrm{TiO}_{2}$ Thin Films Deposited by Vacuum Arc on Ti-6Al-4V Substrates," Journal of Biomedical Materials Research Part B, Vol. 100 , No. 4, 2012, pp. 1078-1085. http://dx.doi.org/10.1002/jbm.b.32674

[31] A. Mihranyan, J. Forsgren, M. Strømme and H. Engqvist, "Assessing Surface Area Evolution during Biomimetic Growth of Hydroxyapatite Coatings,” Langmuir, Vol. 25, No. 3, 2009, pp. 1292-1295. http://dx.doi.org/10.1021/la803520k

[32] J. Sörensen, M. Lilja, T. Sörensen, M. Åstrand, P. Procter, M. Strømme and H. Steckel, "Biomechanical and Antbacterial Properties of Hydroxyapatite Coated Fixation Pins," unpublished.

[33] "HPLC Detection of Gentamicin Sulphate," In: British Pharmacopoeia, London, England, 1999, pp. 695-697.

[34] H. Fabre, M. Sekkat, M. D. Blanchin and B. Mandrou, "Determination of Aminoglycosides in Pharmaceutical Formulations-II. High-Performance Liquid Chromatography," Journal of Pharmaceutical and Biomedical Analysis, Vol. 7, No. 12, 1989, pp. 1711-1718. http://dx.doi.org/10.1016/0731-7085(89)80185-2

[35] M. D’Arrigo, G. Ginestra, G. Mandalari and P. M. Furneri, "Synergism and Postantibiotic Effect of Tobramycin and Melaleuca alternifolia (teatree) Oil against Staphylococcus aureus and Escherichia coli," Phytomedicine, Vol. 17, No. 5, 2010, pp. 317-322. http://dx.doi.org/10.1016/j.phymed.2009.07.008

[36] S. Ban, S. Maruno, N. Arimoto, A. Harada and J. Hasegawa, "Effect of Electrochemically Deposited Apatite Coating on Bonding of Bone to the HA-G-Ti Composite and Titanium," Journal of Biomedical Materials Research, Vol. 36, No. 1, 1997, pp. 9-15.

http://dx.doi.org/10.1002/(SICI)1097-4636(199707)36:1< 9::AID-JBM2>3.0.CO;2-P

[37] J. H. Lee, H. S. Ryu, K. S. Hong, D. S. Lee, K. B. S. Chang and C. K. Lee, "Biomechanical and Histomorphometric Study on the Bone-Screw Interface of Bioactive Ceramic-Coated Titanium Screws,” Biomaterials, Vol. 26, No. 16, 2005, pp. 3249-3257.

http://dx.doi.org/10.1016/j.biomaterials.2004.08.033

[38] U. Brohede, S. Zhao, F. Lindberg A. Mihranyan, J. Forsgren, M. Strømme and H. Engqvist, "A Novel Graded Bioactive High Adhesion Implant Coating," Applied Surface Science, Vol. 225, No. 17, 2009, pp. 7723-7728. 
http://dx.doi.org/10.1016/j.apsusc.2009.04.149

[39] A. Kuhn, T. McIff, J. Cordey, F. W. Baumgart and B. A. Rahn, "Bone Deformation by Thread-Cutting and ThreadForming Cortex Screws,” Injury, Vol. 26, No. 1, 1995, pp. 12-20. http://dx.doi.org/10.1016/0020-1383(95)90117-5

[40] A. W. Kwok, J. A. Finkelstein, T. Woodside, T. C. Hearn and R. W. Hu, "Insertional Torque and Pull-Out Strengths of Conical and Cylindrical Pedicle Screws in Cadaveric Bone,” Spine, Vol. 21, No. 1, 1996, pp. 2429-2434. http://dx.doi.org/10.1097/00007632-199611010-00004

[41] A. F. Tencer and K. D. Johnson, "Biomechanics in Orthopedic Trauma,” In: Bone Fracture and Fixation, M. Dunitz, Ltd, London, 1994, pp. 118-157.

[42] M. Capper, C. Soutis and O. O. A. Onit, "Comparison of the Stresses Generated at the Pin-Bone Interface by Stan- dard and Conical External Fixator Pins,” Biomaterials, Vol. 15, No. 6, pp. 471-473.

http://dx.doi.org/10.1016/0142-9612(94)90227-5

[43] A. Koistinen, S. S. Santavirta, H. Kröger and R. Lappalainen, "Effect of Bone Mineral Density and Amorphous Diamond Coatings on Insertion Torque of Bone Screws,” Biomaterials, Vol. 26, No. 28, 2005, pp. 5687 5694.

http://dx.doi.org/10.1016/j.biomaterials.2005.02.003

[44] S. M. T. Chan, C. P. Neu, K. Komvopoulos and A. H. Redd, "The Role of Lubricant Entrapment at Biological Interfaces: Reduction of Friction and Adhesion in Articular Cartilage,” Journal of Biomechanics, Vol. 44, No. 11, 2011, pp. 2015-2020.

http://dx.doi.org/10.1016/j.jbiomech.2011.04.015 